\title{
Information extraction from biphasic concentration- response curves for data obtained from neuronal activity of networks cultivated on multielectrode- array-neurochips
}

\author{
Kerstin Lenk ${ }^{1 *}$, Matthias Reuter ${ }^{2}$, Olaf HU Schroeder ${ }^{3}$, Alexandra Gramowski ${ }^{3}$, Konstantin Jügelt ${ }^{3}$, Barbara Priwitzer ${ }^{1}$
}

From Nineteenth Annual Computational Neuroscience Meeting: CNS*2010

San Antonio, TX, USA. 24-30 July 2010

We aim to fit biphasic concentration-response curves to extract information about the effect of given biochemical substances to in-vitro neurons.

Neurons extracted from embryonic mice are cultivated on multielectrode-array-neurochips (MEA-neurochip) [1]. The activity of single neurons in such networks is recorded especially the change of network activity caused by long-term application of neuroactive substances. This results in quasi-stable patterns of neuronal activity. Based on the data, different features [2] are calculated adapted from spikes and bursts and separately displayed in concentration-response curves [3]. These concentration-response curves can exhibit non sigmoid shape, then indicating that different mechanisms affect the neuronal activity. Hence, the concentration-response curves presumably include currently hidden and unused information.

\section{Methods}

The concentration-response curve under consideration is given as mean spike rate depending on the logarithm of concentration. We present two methods to calculate biphasic concentration-response curves.

Firstly, a fitting algorithm, extending the method described in [3] is developed, leading not only to monophasic but also biphasic concentration-response curves. The fitting parameters gained with this method exhibit new features describing the effect of neuroactive substances in a new way.

Secondly, a smoothing spline [4] is applied to the data. Thereby efforts are being made to keep close at the data

\footnotetext{
* Correspondence: kerstin.lenk@hs-lausitz.de

'Department of Information Technology/Electronics/Mechanical Engineering, Lausitz University of Applied Sciences, Senftenberg, Brandenburg, Germany
}

as well as to achieve a smooth curve. Computational Geometry is used to calculate the minimal and maximal curvature, the area under the curve as well as the local extrema of the fitted curve. These values quantify concentration dependent effects of the used substances.

We applied both approaches to datasets which are derived by adding agmatine or bicuculline, respectively, to the neuronal network (data by courtesy from Neuroproof $\mathrm{GmbH}$ ). As these substances have biphasic or monophasic concentration-response curves, we were able to compare the values of the new features for these different effects.

\section{Conclusion}

The methods described above lead to new features describing the effect of increasing concentration on the mean spike rate of in-vitro neuronal networks. We aim to use these features for classification with machine learning algorithms like neuronal networks or support vector machines to identify unknown substances.

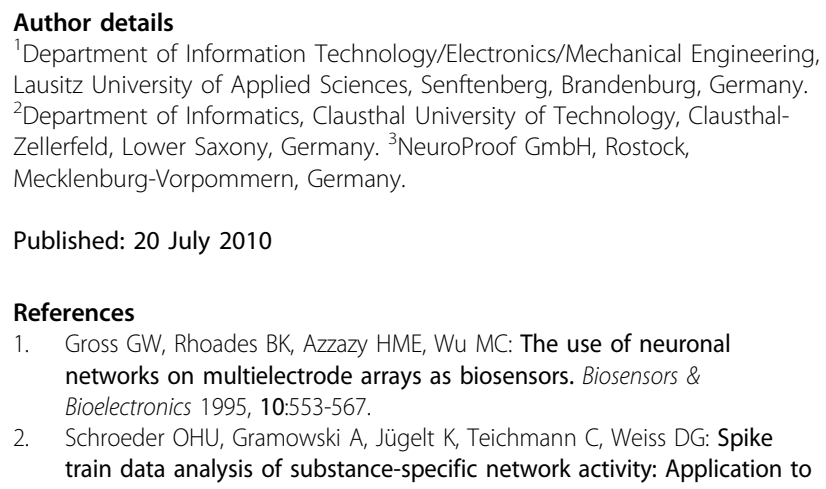
Lausitz University of Applied Sciences, Senftenberg, Brandenburg, Germany. ${ }^{2}$ Department of Informatics, Clausthal University of Technology, ClausthalZellerfeld, Lower Saxony, Germany. ${ }^{3}$ NeuroProof GmbH, Rostock, Mecklenburg-Vorpommern, Germany.

Published: 20 July 2010

References

1. Gross GW, Rhoades BK, Azzazy HME, Wu MC: The use of neuronal networks on multielectrode arrays as biosensors. Biosensors \& Bioelectronics 1995, 10:553-567.

2. Schroeder OHU, Gramowski A, Jügelt K, Teichmann C, Weiss DG: Spike train data analysis of substance-specific network activity: Application to 
functional screening in preclinical drug development. 6th Int. Meeting on Substrate-Integrated Microelectrodes 2008.

3. Motulsky H, Christopoulos A: Fitting Models to Biological Data Using Linear and Nonlinear Regression: A Practical Guide to Curve Fitting San Diego CA: GraphPad Software Inc. 2003 [http://www.graphpad.com].

4. deBoor C: A practical guide to splines, Revised Edition. New York: Springer-Verlag 2001.

doi:10.1186/1471-2202-11-S1-P168

Cite this article as: Lenk et al:: Information extraction from biphasic concentration-response curves for data obtained from neuronal activity of networks cultivated on multielectrode-array-neurochips. BMC Neuroscience 2010 11(Suppl 1):P168.

Submit your next manuscript to BioMed Central and take full advantage of:

- Convenient online submission

- Thorough peer review

- No space constraints or color figure charges

- Immediate publication on acceptance

- Inclusion in PubMed, CAS, Scopus and Google Scholar

- Research which is freely available for redistribution

Submit your manuscript at www.biomedcentral.com/submit 